\title{
A measurement system for very fast transients in GIS power substations
}

\author{
Yan $\mathrm{Wu}^{1}$, Hengtian $\mathrm{WU}^{2 *}$, Lingyun $\mathrm{Gu}^{1}$, Chongqing Jiao ${ }^{3}$ \\ ${ }^{1}$ China Electric Power Research Institute, Beijing, 100192, China; \\ ${ }^{2}$ State Grid Energy Research Institute Co., Ltd., Beijing, 102209, China; \\ ${ }^{3}$ School of Electric and Electronic Engineering, North China Electric Power University, 102206, China.
}

\begin{abstract}
In order to acquire the very fast transients during the disconnector operations in GIS (gas insulated switchgear, GIS) of power substation, a novel measurement system is developed and tested. By using the high speed digitizer as an alternative of the oscilloscope with other auxiliary device, the system is an effective approach to acquire the characteristics of the disturbance voltage of VFTs, including the frequency domain and the time domain features. Several kinds of experiments are carried out in the lab and GIS substation. The results show the good performance of this measurement system.
\end{abstract}

\section{Introduction}

The gas insulated switchgear (GIS) is widely used in power substations of many gird levels. Very fast transient overvoltages (VFTs), caused by discharge process during the disconnector (DS) operations of GIS, directly threaten the insulation of the GIS and even make the secondary power supply device fail[1-3]. The protection measures are needed to protect the devices from VFTs and the measurement of the VFTs is vital for protection formulating. The VFTs are usually measured to acquire the characteristics mainly including the voltage amplitude and frequencies[4-5].

This paper introduces a measurement system for the GIS secondary devices. Based on the resistancecapacitive voltage divider, the primary high voltage is attenuated in proportion to low voltage signals. A high speed digitizer is used to record and transmit the signals to computers for subsequent analysis. Performance tests to this measurement system includes high-voltage DC, square waves, surges and transient enclosure voltage(TEV) measuring, which validate the excellent competency of the system. This measurement system is also applied in a $1000 \mathrm{kV}$ GIS substation and it completes the measuring task well.

\section{Designed specifications}

The VFTs usually have amplitude distribution with great randomness and a wide frequency band[6-8]. The risetime of the voltage reaches nanoseconds level which is quite difficult to catch them. In the standard IEC 610004-18 specifically aimed at power supply devices tests, the harshest voltage level reaches $4 \mathrm{kV}$ with three probable frequencies: $3 \mathrm{MHz}, 10 \mathrm{MHz}$ and $30 \mathrm{MHz}$, all oscillation waves[9].

To meet the requirements, the designed specification of the measurement system is as follows:

(1). Amplitude: the transient voltage level of the system reaches $40 \mathrm{kV}$ to the highest. This level exceeds not only the VFTs of secondary devices but also the GIS shell.

(2). Frequency band and transmission: the frequency band is DC $30 \mathrm{MHz}$. The rise-time is $5 \mathrm{~ns}$ to the fasted with 1000:1 attenuation ratio.

(3). Record: the recording time is $500 \mathrm{~ms}$ to the longest with no less than $300 \mathrm{Ms} / \mathrm{s}$ sampling rate.

\section{System Development}

\subsection{Measurement theory}

A divider is used in this measurement system to attenuate the high voltage to low voltage signals[10-11]. The signals transmits through cables to acquisition devices, like a digitizer or an oscilloscope, and then recorded by the computer. The division principle is showed as Figure 1. Two series connected couples of $R$ and $C$ compose the divider. The original voltage $E$ is attenuated to signal $u(0, t)$ in a proportion by the divider and transmitted to acquisition device the through the cable. The received signal is $u(l, t)$. The wave impedance of the cable is $Z \mathrm{c}$ and the equivalent impedance of acquisition devices is $R_{L}$, $\left(R_{L}>>Z_{C}\right)$.

If the frequency of the voltage is low, the resistance works mainly and the capacitance can be neglected. Otherwise, when dealing with high frequency voltages,

*Corresponding author's e-mail: whtian677@163.com. 
the capacitance works mainly with the resistance neglected. Due to length of the cable is usually $1 \sim 2 \mathrm{~m}$. For VFTs the cable is short enough that the transmission line effect can be ignored. Thus we get $u(l, t) \approx u(0, t)$. This system will obtain a fix attenuation ratio for a wide frequency band through sound configuration of $R$ and $C$.

\subsection{Measurement system configuration}

A high-voltage probe functions as the voltage divider with a high speed digitizer connected to it responsible for dealing with the low voltage single from the probe. The high speed digitizer and a PC connected to each other by fibers compose the acquisition part. The whole system is powered by one Li-battery pack which can run $4 \mathrm{~h}$ to the longest. Other devices including the mother board and the $\mathrm{O} / \mathrm{E}$ converters are installed in a customized shielding box with $50 \mathrm{~mm} \times 470 \mathrm{~mm} \times 97 \mathrm{~mm}$ size as Figure 2 shows.

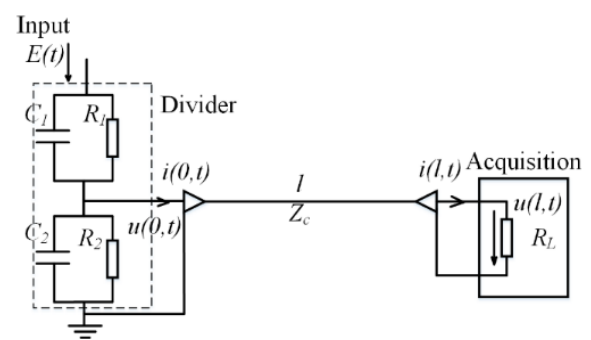

Figure 1. The circuit of the divider of the measurement system

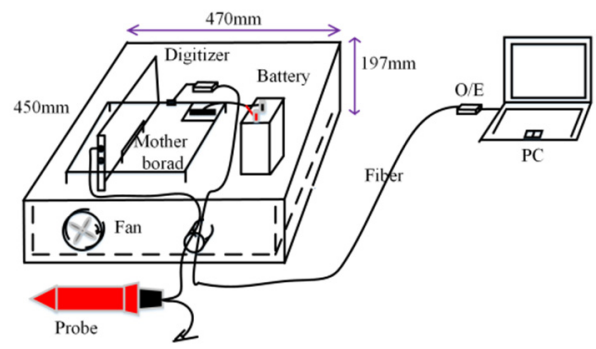

Figure 2. Configurations of the measurement system

Depending on the fans installed in the side wall of the box, the system is excellent in heat radiation. The box shielding effect is $40 \mathrm{~dB}$ when the EM frequency is below $950 \mathrm{MHz}$. The parameters of the system are listed in Table 1.

Table 1. Detailed specifications of high-voltage probe and high-speed digitizer

\begin{tabular}{lll}
\hline Parameters & Probe & Digitizer \\
\hline Model & Pintech-6039A & NI-PCI \\
Peak voltage & $40 \mathrm{kV}$ & $40 \mathrm{~V}$ \\
Input impedance( $\boldsymbol{\Omega})$ & 900 & $50 / 1$ \\
Rise-time(ns) & 1.6 & 1.4 \\
Bandwidth(MHz) & DC 220 & - \\
Storage(MB) & - & 256 \\
Attenuation ratio & $1000: 1$ & - \\
Sampling rate(GS/s) & 2.5 & - \\
\hline
\end{tabular}

\section{Tests}

\subsection{High-voltage DC}

To validate the insulation of the DC measuring performance, this test is carried out in the lab. The electrodes of a calibrated high-voltage DC power source are connected to two plane plates respectively. The voltages are measured between the plates and the results are recorded. As is shown in Figure 3, the measured data is in line with the power source voltages. The range of the power source is $0 \sim 30 \mathrm{kV}$ with a $3 \mathrm{kV}$ interval. The max and min of absolute errors are 1.09 and $0.03 \mathrm{kV}$ respectively. The max and min of relative errors are $3.6 \%$ and $0.6 \%$ which are precise very much.

\subsection{Square waves}

Square waves produced by the waveform generator are also measured in the lab to verify the high-frequency response performance of the system. The amplitude of the squares are $10 \mathrm{kV}$ to $-10 \mathrm{kV}$ with $50 \%$ duty circle and the period is $2 \mu \mathrm{s}$. The results and some details are shown in Figure 4. The rise-time of the step of the square is $5.04 \mathrm{~ns}$, which is the time from $10 \%$ to $90 \%$ of the voltage amplitude. The frequency bandwidth is $70 \mathrm{MHz}$ via the calculation $B W=0.35 / R T$. Namely, the system can measure signals with $70 \mathrm{MHz}$ of frequency to the most, which is wide enough to cover the frequencies of VFTs.

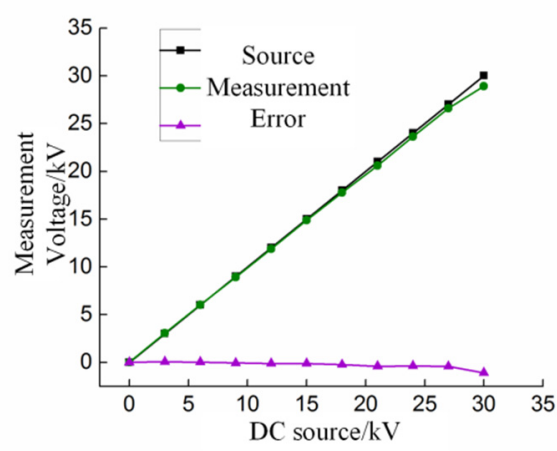

Figure 3. High voltage DC measurement

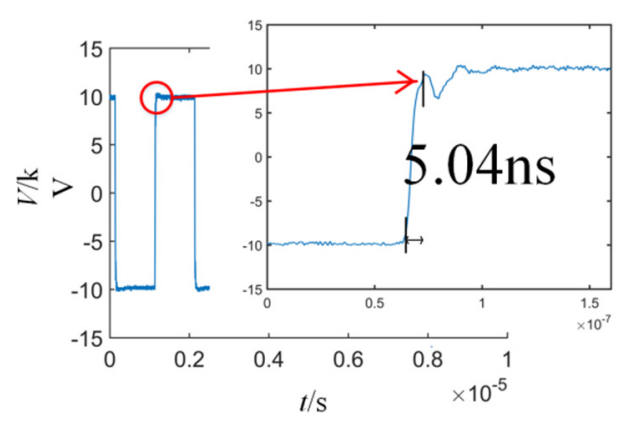

Figure 4. Square wave measurement 


\subsection{Surge waves}

The surges produced by the combined wave generator are measured in this test. The generator is intended to generate a surge having an open-circuit voltage front time of $1.2 \mu \mathrm{s}$ and open-circuit duration of $50 \mu \mathrm{s}$, which is applied to the probe of the measurement system. The open-circuit output peak voltage is adjusted to $5.5 \mathrm{kV}$. The captured waveform is shown as Figure 5. The measured peak is $5.58 \mathrm{kV}$ and the relative error is $1.6 \%$. The rise-time is $1.24 \mu$ s with the relative error of $3.3 \%$. The duration is $49.48 \mu$ s with the relative error of $1 \%$. The results meet the specification of the IEC.

\subsection{TEV}

The transient enclosure voltage is typical one of VFTs [12-13]. During the switching operation, the transient voltages between the GIS shell and the ground is defined as the transient enclosure voltage (TEV). The amplitude of TEV usually reaches tens of $\mathrm{kV}$ and the frequencies of it are as high as dozens of MHz. The TEV measurement is an effective mean to verify the measurement system. In a GIS test circuit, the experiment is carried out and the waveform is shown in Figure 6. Besides the system in this paper, another measurement been proven in practice is used in comparison [14-15]. After 10 switching operations, the results including amplitudes difference $(\Delta)$ of two systems, main frequency are listed in Table 2. To be clear, the data in Table 2 are average values of 10 operations.

Table 2. Results of experiment in contrast

\begin{tabular}{llll}
\hline Items & $\begin{array}{l}\Delta \text { of Positive } \\
\text { Peaks(kV) }\end{array}$ & $\begin{array}{l}\Delta \text { of Negative } \\
\text { Peaks(kV) }\end{array}$ & $\begin{array}{l}\text { Frequency } \\
(\mathrm{MHz})\end{array}$ \\
\hline $\begin{array}{l}\text { System in } \\
\text { this paper }\end{array}$ & 0.26 & 0.27 & 7.5 \\
$\begin{array}{l}\text { Proven } \\
\text { system }\end{array}$ & & & 7.8 \\
\hline
\end{tabular}

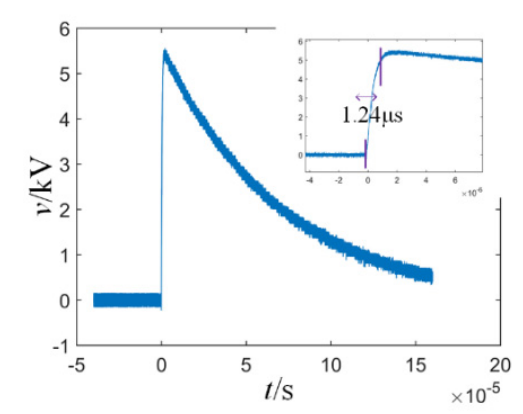

Figure 5. Surge voltage measurement

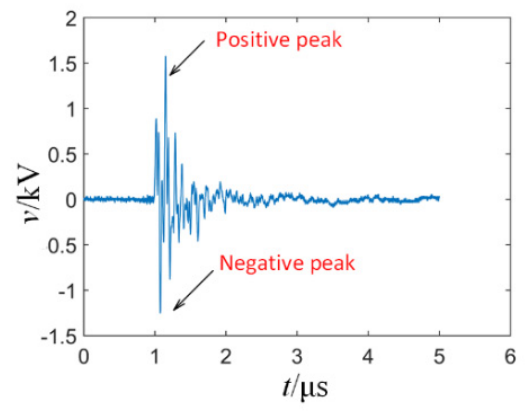

Figure 6. TEV measurement

\section{Application}

The system is applied in a $1000 \mathrm{kV}$ GIS substation to measure the VFTs of secondary devices in the local cabinet. Figure 7 shows the arrangement. The voltage probe is connected between the port for monitoring of the secondary devices and the ground. The measurement system is placed outside the cabinet. The transient waveforms are shown in Figure 8.

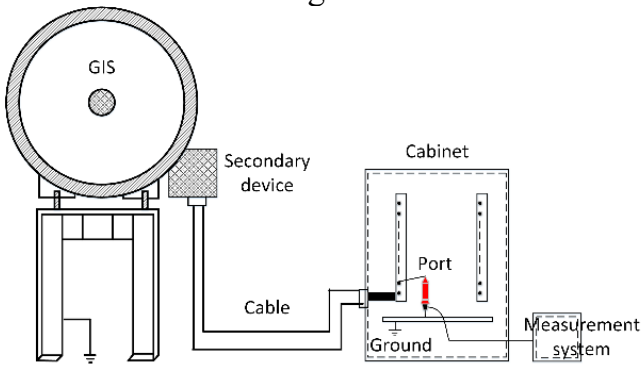

Figure 7. The layout of the measurement

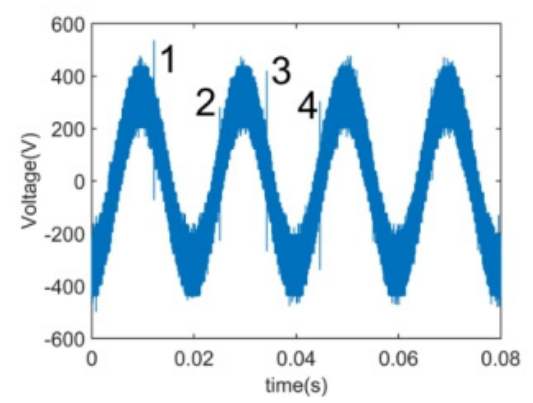

Figure 8. VFTs waveform

In this observation, there are four obvious VFTs superposed on the $50 \mathrm{~Hz}$ sine-wave. The max amplitude of the voltage is close to $600 \mathrm{~V}$. The details of VFT 4 in $\mu$ s timescale are shown in Figure 9 and 10. The voltage is a typical damped oscillation wave. The oscillation lasts about $1 \mu \mathrm{s}$. The main frequency is $14 \sim 30 \mathrm{MHz}$. The max frequency reaches $100 \mathrm{MHz}$.

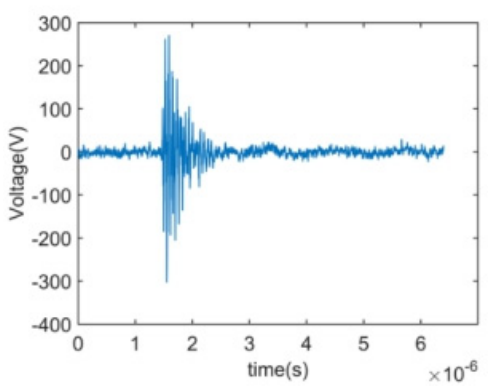

Figure 9. The layout of the measurement

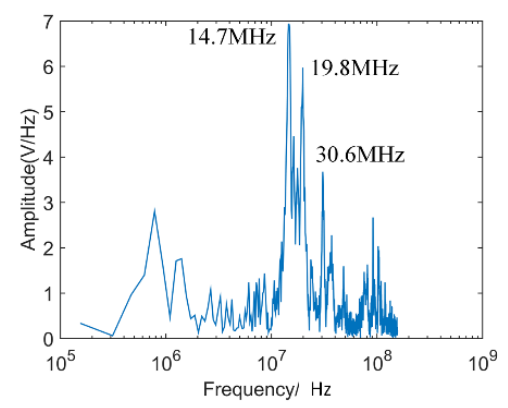

Figure 10. VFTs waveform 


\section{Conclusion}

(1) Based the voltage-divide theory, the measurement system specially for VFTs is developed by using the high-voltage probe as the sensor and the digitizer as the acquisition device.

(2) Tests including the high-voltage DC, square wave, surge wave and TEV measurement are carried out in this paper to examine the measurement system and the results show the good performance of it.

(3) The application of this measurement system in the $1000 \mathrm{kV}$ GIS substation is completed successfully. The reliability and the stability of it in measuring VFTs are reflected in the test.

\section{Acknowledgments}

This work was supported by the Science and Technology Project of SGCC "Research and Application on the Key Technology of Primary and Secondary Fusion Distribution Switchgear".

\section{References}

1. Chen W J, Zhao J, Bian K, et al. (2019) Research progress on transient electromagnetic disturbance due to switching operations in GIS substation. Proceedings of CSEE, 39:4925-4948.

2. Zhao D D, Liu Z L, Han Z, at al. (2019) Effect of UHV circuit breaker pre-breakdown on switching overvoltage when closing unloaded GIS bus. High Voltage Apparatus, 55:0018-0024.

3. Wu Q, Liu X M, Yang T, et al. (2018) Numerical analysis method for transient insulation of GIS under lightning impulse voltage. High Voltage Engineering, 44:4098-4104.

4. Kong X, Guo F, Liang T, et al. (2016) Measurement and analysis of the transient radiation electric field excited by the breaker when closing the unloaded transformer in GIS. Proceedings of CSEE, 36:50875093.

5. Gan Z Y, Zhao J, Zhang J G, et al. (2016) Computation of transient electromagnetic field emission from enclosure during gis disconnector switching operations. High Voltage Engineering, 42:980-986.

6. Zhao L, Ye L Y, Yang Y, et al. (2018) Simulation study on very fast transient overvoltage during operation of $550 \mathrm{kV}$ GIS disconnector. Zhejiang Electric Power, 37:86-92.

7. Magne R. (2013) Failure Frequencies for HighVoltage Circuit Breakers, Disconnectors, Earthing Switches, Instrument Transformers, and GasInsulated Switchgear. IEEE Transients on Power Delivery, 28:529-530.

8. Shigemitsu O, Jun T; Kenichi N. (2008) Phenomena of leaking electromagnetic waves and high frequency surges from isolated joint of gas insulated switchgear, IEEE Transactions on Dielectrics and
Electrical Insulation, 15:1006-1014.

9. IEC Standard 61000-4-18 , 2006-11 Electromagnetic Compatibility(EMC)-Part 4-18 : Damped oscillatory wave immunitytest.2006

10. Yue G C, Liu W D, Chen W J et al. (2013) Development of full frequency bandwidth measurement of VFTO in UHV GIS, IEEE Transactions on Power Delivery, 28:2550-2557.

11. Lu Z, Sen W, Lei S, (2018) Prediction model of voltage-time characteristics for SF6 long gap under VFTO and lightning impulse voltage, IET Generation, Transmission \& Distribution, 12: 880885.

12. Marcin S, Maciej K. (2017) Controlled voltage breakdown in disconnector contact system for VFTO mitigation in gas-insulated switchgear (GIS). IEEE Transactions on Power Delivery, 32: 2360 2366.

13. He J X, Yue G C, Liu W D, et al. Design optimization of ferrite rings for vfto mitigation. IEEE Transactions on Power Delivery, 32:11811186.

14. Hu R, Cui X, Zhang W D, et al. (2012) Transient Enclosure Voltage (TEV) measurement system of UHV GIS and TEV statistical characterization. International Symposium on Electromagnetic Compatibility - EMC EUROPE.

15. Hu R, Cui X, Chen W J, et al. (2015) Development of the measuring device of transient enclosure voltage in ultra high voltage gas insulated switchgear. Proceedings of CSEE, 35: 6235-6245. 